\title{
The impact of general health and social support on health promoting lifestyle in the first year postpartum: the structural equation modelling
}

\author{
Khadijeh Hajimiri ${ }^{1}$, Elham Shakibazadeh ${ }^{2}$, Ali Asghar Haeri Mehrizi ${ }^{3}$, Sakineh Shabbidar ${ }^{4}$, Roya Sadeghi ${ }^{2}$
}

${ }^{1}$ Ph.D. Candidate of Health Education and Promotion, Department of Health Education and Promotion, School of Public Health, Tehran University of Medical Sciences, Tehran, Iran

${ }^{2}$ Ph.D. of Health Education, Associate Professor, Department of Health Education and Health Promotion, School of Public Health, Tehran University of Medical Sciences, Tehran, Iran

${ }^{3}$ M.Sc. of Statistics, Faculty Member, Health Metrics Research Center, Iranian Institute for Health Sciences Research, ACECR, Tehran, Iran

${ }^{4}$ Ph.D. of Nutritional Sciences, Assistant Professor, Department of Community Nutrition, School of Nutritional Sciences and Dietetics, Tehran University of Medical Sciences, Tehran, Iran

\section{Type of article: Original}

\begin{abstract}
Background and aim: Postpartum is a critical period for mothers which often leads to neglect of their own health. Mothers' new responsibilities may affect their health promoting lifestyle (HPL). The aim of this study was to determine the impact of both general health and social support on health-promoting lifestyle.

Methods: A cross-sectional survey was conducted on 310 women who gave birth over a one-year period in Zanjan (Iran), 2016. A proportionate stratified random sampling technique was used to select respondents from each stratum. Health-promoting lifestyle was assessed using the health-promoting lifestyle profile II (HPLP II) scale. A structure equation model (SEM) was used to determine the relationship between observed and latent variables. Data were analysed using SPSS version 22 and LISREL 8.5 software.

Results: The age of $42.6 \%$ of the participants was more than 30 years and $40.3 \%$ of them had an academic education. The mean score of the health-promoting lifestyle was 131.28 (15.37). The structural equation model fitted well with RMSEA $=0.07, \mathrm{CFI}=0.92$, and GFI $=0.94$. Among the latent factors, general health, with a factor load of -0.68 , had greater impact on health-promoting lifestyle than social support. Moreover, there was a significant correlation $(-0.63)$ between general health and perceived social support in the postpartum period.

Conclusion: health-promoting lifestyle was not at appropriate levels among women in the first year after delivery. These findings suggest that strengthening general health and social support would improve a healthpromoting lifestyle in Iranian postpartum women.

Keywords: Postpartum Period, Life Style, Social Support
\end{abstract}

\section{Introduction}

The postpartum period is a critical transitional stage in the lives of mothers, and it starts from delivery and lasts from between 1 and 3 years (1). This period is characterized by several physiological, emotional, and psychosocial changes (2). In this period, mothers are expected not only to take new maternal responsibilities but also to play their normal roles in the family. These roles and responsibilities are often difficult to coordinate. Therefore, they may lead to feelings of stress and pressure in the mothers (3). The difficulty of a new condition as well as the multitude of responsibilities may not only affect the mother's health behaviours (4) but also threaten her quality of life and physical and mental well-being (5). Both fatigue and lack of time may have negative impacts on mothers' healthpromoting behaviours so that adhering to structured diet and exercise are difficult $(6,7)$. Fatigue can also affect the

\section{Corresponding author:}

Associate Professor Dr. Roya Sadeghi, Department of Health Education and Health Promotion, School of Public Health, Tehran University of Medical Sciences, Tehran, Iran.

Tel: +98.2188955888, Fax: +98. 2188989129, Email: sadeghir@tums.ac.ir

Received: April 23, 2017, Accepted: July 28, 2017, Published: January 2018

iThenticate screening: July 30, 2017, English editing: January 12, 2018, Quality control: January 15, 2018

(C) 2018 The Authors. This is an open access article under the terms of the Creative Commons Attribution-NonCommercialNoDerivs License, which permits use and distribution in any medium, provided the original work is properly cited, the use is non-commercial and no modifications or adaptations are made. 
mother's stress response, and even last until the third year into postpartum, preventing adaption to the role of motherhood, and putting the mother's mental health in danger (8). Women who suffer from postpartum mental disorders may not be able to handle their responsibilities well. They may not even have health promoting behaviours, which may also have great negative impacts of their health in the coming years (9). Studies have shown that the months following delivery are frequently characterized by mental disorders. Almost $13 \%$ of women in developed countries, and even more so in developing countries experience a depressive illness within 1 year postpartum (10). A recent systematic review and meta-analysis in Iran also showed that the prevalence of postpartum depression as a mental disorder was $25.3 \%$ (95\% CI: $22.7 \%-27.9 \%)$ (11). Fortunately, the mother's perceptions of the amount of positive social support she is receiving after delivery has been related to decreased stress levels and to a better health status (9). So, social support has an important role in coping with stress (12). The support provided by spouse and family could make some of the mothers' daily tasks easier, and alleviate the maternal fatigue (13). Such support may allow the mothers to relax and to address their own issues, leading to reduced stress and an improved health condition. Mothers in the postpartum period have reported that help received from their spouse and mothers, both with housework and baby care, would be of great importance to them (14). Women who are better supported are less likely to develop health problems. Thus, having a good relationship with family and friends has a positive effect on the mothers' ability to fulfill their roles as well as their physical and mental well-being (15). Transition to motherhood is a psychologically stressful event, which can be facilitated by the support of women (14). In Iran, family ties play a higher role in social interaction. Iranian women who were either pregnant or in the postpartum period, normally enjoyed cordial family relationships, and could count on the help of their mothers and mother in laws in supporting caring for their babies. After delivery, the family helps mothers in tasks and take care of them at home for at least 40 days. Also, as suggested by Mirghafoorvand et al. (16), many Iranian families still live as an extended household, which ensures closer interpersonal relations and social support. But, one of the important issues about women in the postpartum period is that they put their health at secondary importance because of child care (17). Therefore, attention to women's health, not only during pregnancy but also after delivery, is also an important matter especially because the women's health directly affects the children's health. On the other hand, women's health promoting lifestyle in the first year after child birth has not been well documented. Thus, this study aimed to determine the level of engaging of health promoting lifestyle by mothers in the first year after childbirth and the impact of general health and social support on women's healthpromoting lifestyle. The following research questions were addressed: (a) What is the health promotion lifestyle (HPL) among mothers in the first year after childbirth? (b) What are the impacts of general health and social support on mothers' health-promoting lifestyle?

\section{Material and Methods}

\subsection{Research design}

A cross-sectional study design was conducted on post-partum women attending governmental health centers in Zanjan town, Iran in 2016. Source populations were all women who gave birth over a one-year period; and study populations were all sampled, and 310 women (18-45 years) from source populations who received care (vaccination for one-year-old) who were present during the study period were included. The inclusion criteria were having a single, healthy, one-year-old child; and also, a lack of health problems in mothers (chronic disease of the heart, liver, or kidney problems, moderate or severe depression), and lack of pregnancy within a year after giving birth.

\subsection{Conceptual framework}

The conceptual framework (Figure 1) is supporting the research underpinned by social cognitive theory (SCT). This theory emphasizes that human behaviour depends on the reciprocal interaction of personal, behavioural, and environmental factors (18). It was hypothesized that perceived social support (socio- environmental factor) and general health (personal factor) had an impact on HPL (behaviour).

\subsection{Sample size and sampling procedure}

The required sample size was determined as 274 , using single population formula by considering the mean (SD) 2.83 (1.35) health promoting behaviours based on the previous study (9). Based on the above assumptions, with an additional 10 percent contingency for non-response, the total sample size was 310. This sample size for SEM analysis seems to be enough because the minimum sample size should not be lower than 200 or 5-20 times the number of parameters to be estimated (19). Proportionate stratified random sampling technique was used to recruit participants from 14 governmental health centers in Zanjan. For this purpose, each health center was considered as a stratum. Then, based on the number of pregnant women referred to the health centers, the number of samples of 
each health center was determined. In the next step, the list of women who had given birth in the past 11 months was extracted, and samples were selected randomly. Simple random sampling was performed using the SPSS version 22.0 to select case menu. Then, the health records of women were reviewed and those who met the inclusion criteria were contacted by telephone calls and invited to the study. Women who were not willing to participate in the study were replaced with new ones on a random basis.

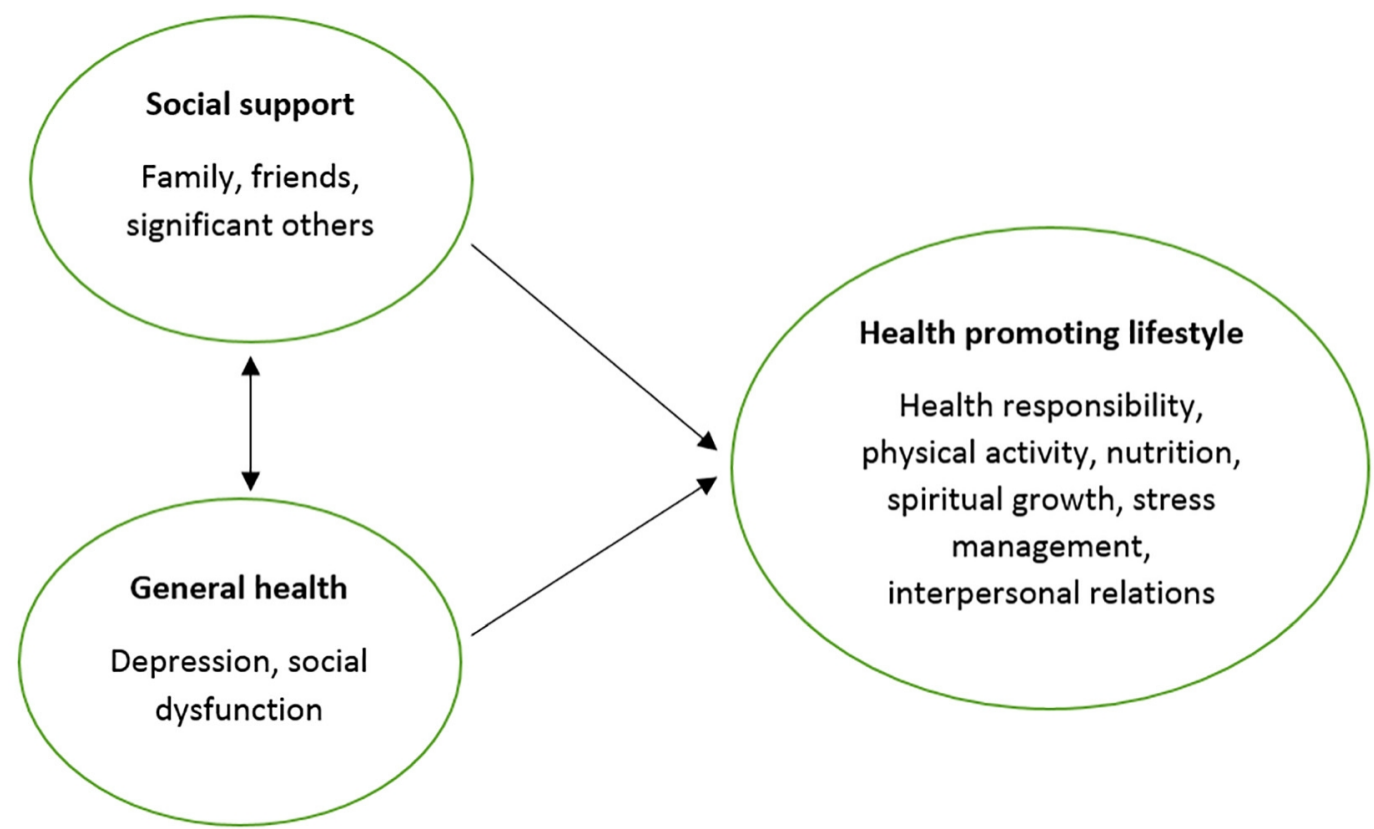

Figure 1. A conceptual framework based on SCT describing social support (Family, Friends, and Significant Other), general health (Depression and Social Dysfunction) and health promoting life style (Health Responsibility, Physical Activity, Nutrition, Spiritual Growth, Stress Management, and Interpersonal Relations).

\subsection{Instruments}

The research instrument included a questionnaire consisting of 4 parts: The first part addressed characteristic variables (age, parity, job status, breastfeeding, delivery, BMI, and education level). The second part was a Health Promotion Lifestyle Profile II (HPLP II) scale: The Persian version of HPLP II, with adequate internal consistency for the 52-item scale (Cronbach's $\alpha=0.82$ ), was used (20). This scale measures the HPL in six dimensions: Health Responsibility, Physical Activity, Nutrition, Spiritual Growth, Stress Management, and Interpersonal Relations. Dimension response range was from 1 to 4, with higher scores indicating better HPL. The third part was a General Health Questionnaire (GHQ): It was adapted into Persian with adequate internal consistency for the 12 -item scale (Cronbach's $\alpha=0.87$ ) with two domains, depression and social dysfunction (21). This questionnaire measures the general health, which uses 4-point Likert scales from 0 to 3, with higher scores indicating a higher level of psychological distress. The fourth part was a Multidimensional Scale of Perceived Social Support: It was adapted into Persian with adequate internal consistency for the 12-item scale (Cronbach's $\alpha=0.84$ ) (22). Dimension response range was from 1 to 7 with higher scores indicating greater support from a significant other, family, and friends. Women's weights were measured, with minimum clothing, using a calibrated digital scale (Seca) with an accuracy of $100 \mathrm{~g}$. The height was measured while standing and keeping the shoulders and hips against the wall without shoes, using the standard Seca stadiometer with an accuracy of $0.1 \mathrm{~cm}$. Body mass index (BMI) was calculated by dividing weight in kilograms by the square of height in meters (23).

\subsection{Statistical analysis}

Descriptive analysis of the data was performed using IBM@ SPSS $\odot$ Statistics version 22 (IBM $\odot$ Corp., Armonk, NY, USA). Parametric tests were used according to the kurtosis, skewness. Pearson's product-moment correlation coefficient was used to measure the linear relationship between continuous variables, but Spearman's rank correlation coefficient was used to measure the strength and direction of the association between two ranked variables. Next, multiple regression analyses were performed to examine the contribution of characteristics (age, parity, job status, breastfeeding, sleep, delivery, BMI, and education level) to the variables (HPL, general health, and 
social support). Direct effects of one factor on the others were estimated by path coefficients proximal to the unidirectional. In this study, we used a structure equation model (SEM) to determine the relationship between observed and latent variables. SEM could show direct and indirect relationships between variables by path maps. Also, whether the relationships are reasonable could be survey based on the results of SEM. The SEM was made using LISREL 8.5 (Scientific Software International Lincolnwood, IL, USA). Chi Square ( $\chi 2$ ), RMSEA (root mean square error of approximation), SRMR (standardized root mean square residual), GFI (goodness-of-fit index), and AGFI (adjusted goodness-of-fit index) were applied to indicate whether the model was an adequate fit. Based on the literature, the factor loads of the structure equation model was accepted as low (under 0.10), medium (around 0.30), and good (over 0.50) without considering its sign (19).

\subsection{Ethical Consideration}

The study design was disclosed to and confirmed by the ethics committee of the research department of Tehran University of Medical Sciences (ID code: 9121108013) as part of a Ph.D. thesis in the field of health education and promotion. After providing all participants with sufficient information about the study, they were asked to sign a written consent form before participating.

\section{Results}

\subsection{Participant characteristics}

The participants' characteristics are shown in Table 1. Average responses to HPL, social support, and general health dimensions are summarized in Table 2. Among the dimensions of health promoting lifestyle, the highest mean (SD) was observed in spiritual growth 25.64 (4.5), and the lowest was observed in physical activity 14.68 (3.41).

Table 1. Participant Socio-Demographic characteristics

\begin{tabular}{|l|l|l|l|}
\hline Variables & $\mathrm{n}$ & $\%$ \\
\hline \multirow{2}{*}{ Age (year) } & $\leq 30$ & 178 & 57.4 \\
\cline { 2 - 4 } & $>30$ & 132 & 42.6 \\
\hline \multirow{5}{*}{ Education level } & Middle school & 40 & 12.9 \\
\cline { 2 - 4 } & high school & 23 & 4.7 \\
\cline { 2 - 4 } & Diploma & 122 & 39.4 \\
\cline { 2 - 4 } & Associated Degree & 30 & 9.7 \\
\cline { 2 - 4 } & Bachelor's Degree or higher & 95 & 30.6 \\
\hline \multirow{3}{*}{ Occupation } & Housewife & 257 & 82.9 \\
\cline { 2 - 4 } & Employed & 53 & 17.1 \\
\hline \multirow{3}{*}{ Parity } & Primiparus & 167 & 53.9 \\
\cline { 2 - 4 } & Multiparous & 143 & 46.1 \\
\hline \multirow{3}{*}{ BMI } & not overweight/obese[BMI <25] & 165 & 53.2 \\
\cline { 2 - 4 } & overweight/obese [BMI $\geq 25]$ & 145 & 46.8 \\
\hline \multirow{2}{*}{ Delivery } & NVD & 155 & 50 \\
\cline { 2 - 4 } & C/S & 155 & 50 \\
\hline \multirow{2}{*}{ Breast feeding } & yes & 240 & 77.4 \\
\cline { 2 - 4 } & no & 70 & 22.6 \\
\hline
\end{tabular}

NVD, Normal Vaginal Delivery; C/S, cesarean section

Table 1. Means, Standard Deviations, Minimum, and Maximum of Constructs and HPLP II ( $n=310)$

\begin{tabular}{|l|l|l|l|l|l|l|l|l|l|l|l|}
\hline \multirow{2}{*}{ Variables } & \multicolumn{4}{l}{ HPLPII } & \multicolumn{3}{l|}{ Social support } & \multicolumn{3}{l|}{ General health } \\
\cline { 2 - 13 } & SG & IR & HR & Nu & SM & PA & Fam & Fri & SO & Dep & SD \\
\hline Mean & 25.64 & 25.32 & 24.59 & 23.90 & 17.15 & 14.68 & 21.52 & 15.53 & 21.09 & 6.56 & 5.05 \\
\hline Standard deviation & 4.5 & 4.04 & 4.42 & 3.09 & 3.73 & 3.41 & 3.4 & 4.6 & 2.8 & 2.09 & 2.19 \\
\hline Min-Max $^{1}$ & $14-36$ & $15-35$ & $9-36$ & $16-32$ & $8-28$ & $8-23$ & $12-28$ & $4-25$ & $14-28$ & $1-13$ & $0-11$ \\
\hline Range scale $^{2}$ & $9-36$ & $9-36$ & $9-36$ & $9-36$ & $8-32$ & $8-32$ & $4-28$ & $4-28$ & $4-28$ & $0-21$ & $0-15$ \\
\hline
\end{tabular}

SG, Spiritual Growth; IR, Interpersonal Relations; HR, Health Responsibility; Nu, Nutrition; SM, Stress

Management; PA, Physical Activity; Fam, Family; Fri, Friend; SO, Significant Others; Dep, Depression; SD, Social

Dysfunction. ${ }^{1}$ The lowest and highest values that were obtained in this study. ${ }^{2}$ The lowest and highest values that can be obtained in the original scale. 


\subsection{The impact of general health and social support on HPL}

At first, correlations among all variables were examined. The relationships among the variables are summarized in Table 3. The strength of the correlation was interpreted based on Cohen's (1988) guideline. So, we considered ' $r$ ' from $0.10-0.29$ as a small or weak correlation, ' $r$ ' from $0.30-0.49$ as either medium or moderate correlation, and ' $r$ ' from 0.50-1.00 as a large or strong correlation (24). Results explain that variables were correlated with each other in a way that supported the hypothesized interrelationships among the factors. Specifically, social support positively and general health were negatively correlated with HPL ( $\mathrm{r}$ ranged $0.497,-0.605$ respectively, $\mathrm{p}<0.001$ ). There was not any significant correlation between characteristics variables with HPL. But, significant correlations were seen between some characteristics variables with social support and general health. However, these correlations were weak (ranging ' $r$ ' from 0.115 to 0.196 ). The next step, multiple regression analyses, were performed to examine the contribution of participants' characteristics (age, parity, job status, breastfeeding, sleep, delivery, BMI, and education level) to the variables (HPL, general health, and social support). Multiple regression results confirmed that participants' characteristics explained a small percentage of variance across all variables (HPL, general health, and social support) $(\mathrm{R} 2$ in HPL $=0.01$; social support $=0.06$; general health $=0.03$ ). As a result of their limited contribution, characteristics variables were not included in the subsequent analyses. Finally, using SEM, the impact of variables on each other was evaluated. Additionally, this method was used to evaluate the measurement accuracy of HPL, social support, and general health as well as the relationship between the latent variables. This model, also, examined the effect of two latent variables of social support and general health (independent variables) on the latent variable of HPL (dependent variable). In this study, the $t$-values about testing the model is examined, it is seen that its overall is over 1.96. Fit indices of the model tested in the study have been determined in Table 4 and they demonstrated that fit of the structural model can be acceptable. The item loads for the six health promoting lifestyle domains were high (ranging from 0.43 to 0.63 ). The factor load between HPL and general health was -0.68 , which was higher than the load between HPL and social support. For social support, the item loads for family, significant other, and friends were $0.69,0.66$ and, 0.25 respectively. The relationships between general health and HPL are depicted in Figure 2.

Table 2. Correlations among the health promoting lifestyle, social support, general health, and participant characteristics

\begin{tabular}{|c|c|c|c|c|c|c|c|c|c|c|c|}
\hline Variables & 1 & 2 & 3 & 4 & 5 & 6 & 7 & 8 & 9 & 10 & 11 \\
\hline $\begin{array}{l}\text { 1-Health Promoting } \\
\text { Lifestyle } †\end{array}$ & 1 & & & & & & & & & & \\
\hline 2-Social Support $\dagger$ & $0.49^{* *}$ & 1 & & & & & & & & & \\
\hline 3-General Health $\dagger$ & $-0.60^{* *}$ & $-0.33^{* *}$ & 1 & & & & & & & & \\
\hline 4-Education $\dagger \dagger$ & 0.02 & $0.13^{* *}$ & -0.1 & 1 & & & & & & & \\
\hline 5-Parity $\dagger \dagger$ & 0.1 & $0.18^{* *}$ & -0.05 & $-0.15^{* *}$ & 1 & & & & & & \\
\hline 6-breastfeeding $\dagger \dagger$ & 0.07 & 0.05 & $-0.19^{* *}$ & 0.07 & -0.03 & 1 & & & & & \\
\hline 7- Job status $\dagger \dagger$ & -0.02 & $0.15^{* *}$ & -0.05 & $0.5^{* *}$ & -0.02 & 0.10 & 1 & & & & \\
\hline 8-Sleept广 & -0.05 & -0.006 & -0.01 & -0.13 & $-0.16^{* *}$ & 0.05 & $-0.28^{* *}$ & 1 & & & \\
\hline 9-Delivery† & -0.02 & 0.006 & 0.03 & $-0.20^{* *}$ & 0.08 & -0.10 & $-0.23^{* *}$ & 0.04 & 1 & & \\
\hline 10-Aget† & -0.03 & $0.11^{*}$ & 0.07 & $0.11^{*}$ & $0.40^{* *}$ & 0.03 & $0.26^{* *}$ & $-0.13^{*}$ & -0.10 & 1 & \\
\hline $11-\mathrm{BMI} \dagger \dagger$ & -.02 & 0.02 & 0.01 & -.006 & -.05 & $-0.12^{*}$ & -0.03 & $0.16^{* *}$ & 0.07 & -0.03 & 1 \\
\hline
\end{tabular}

Table 4. IBM $\odot$ SPSS $\odot$ Statistics version 22 (IBM@ Corp., Armonk, NY, USA) Structural equation model fitness indices

\begin{tabular}{|l|l|l|l|l|l|l|l|}
\hline$\chi 2$ & $\mathrm{df}$ & $\chi 2 / \mathrm{df}$ & GFI & CFI & NFI & AGFI & RMSEA \\
\hline 105.66 & 37 & 2.85 & 0.94 & 0.92 & 0.89 & 0.90 & 0.07 \\
\hline
\end{tabular}

GFI: Goodness of fit index; CFI: Comparative fit index; NFI: Normed fit index; AGFI: Adjusted goodness-of-fit index; RMSEA: Root mean square error of approximation 


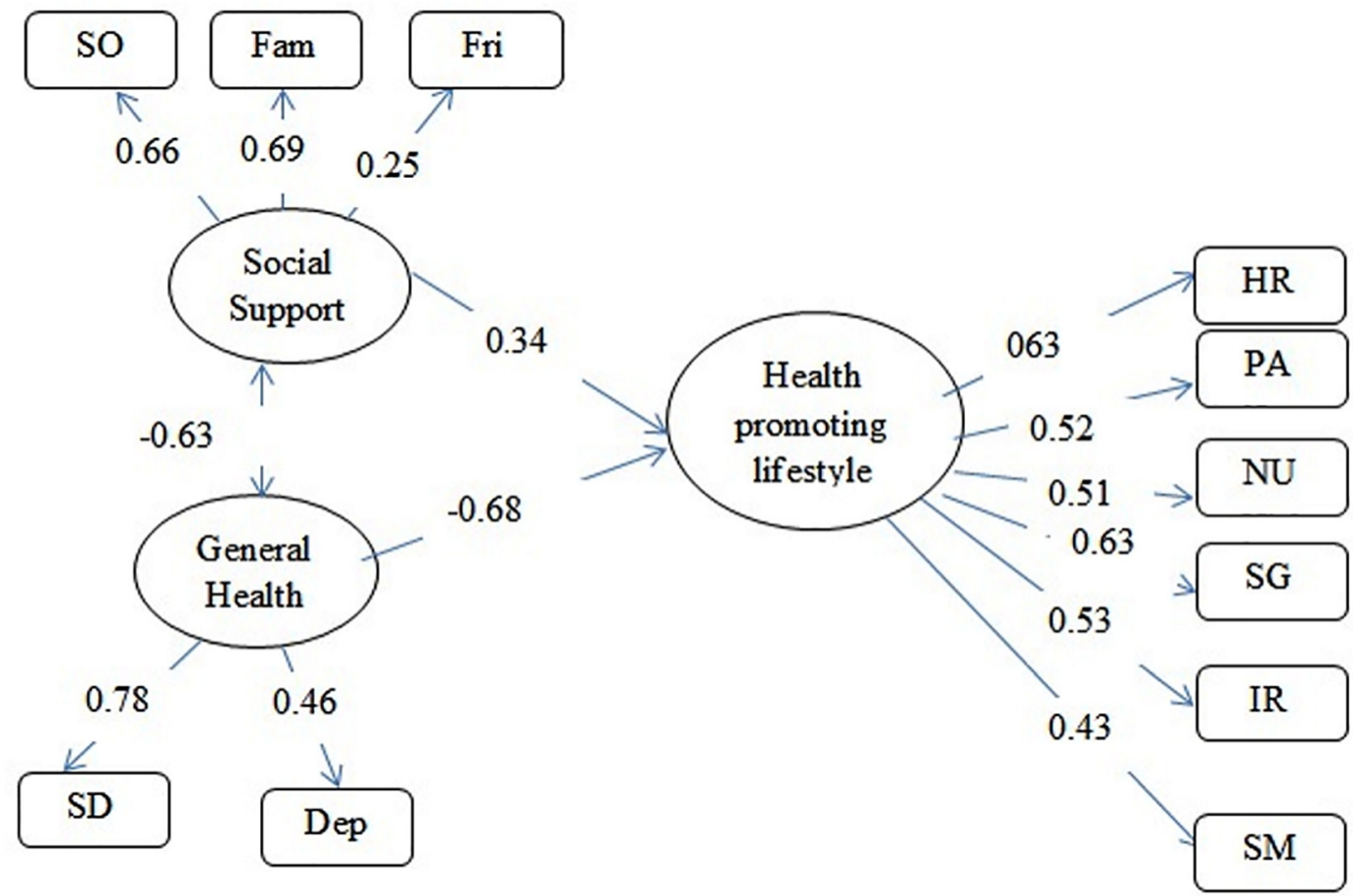

Figure 2. The structural equation modeling of the factors that influence HPL among postpartum women. Path diagram is illustrating the relationships between social support, general health, and HPL. General health had the greatest impact on health promoting lifestyle. SO, Significant Others; Fam, Family; Fri, Friends; Sd, Social Dysfunction; Dep, Depression; HR, Health Responsibility; PA, Physical Activity; NU, Nutrition; SG, Spiritual Growth; IR, Interpersonal Relations, SM; Stress Management.

\section{Discussion}

Promotion of health after childbirth is an important contributor to women's well-being. Because, the new roles and responsibilities, that come with a baby, induce many women to give up or limit health promoting behaviours after childbirth (4). The output of this study confirmed that the SEM fits our data well. For the latent factors, general health had a greater impact on HPL than the social support. For the observed variables, the item loads for social support from family and other significant, were higher than friends support. For the observed general health, the greatest item loads were seen for social function than depression. This study, also, found a significant indirect relationship between social support and general health, which suggests that women who receive limited social support are more likely to be exposed to general health problems. The impact of social support on both mental health and postpartum depression has been investigated in several studies, which have all confirmed the presence of such effect $(9,25)$. The mothers who are either depressed or suffer from other mental health issues are also less likely to seek social support as their depression may inhibit their ability to recognize the need for such support (26). Also, many mothers with either depression or psychological distress who recognize their need for social support might not be able to mobilize the necessary support. Our results indicated that social support had a positive impact on women's health promotion life style. Previous studies have also shown that social support has a positive impact on the HPL $(16,27)$. Higher social support will predict better physical, mental and cognitive health (28). Studies have shown that social support during the postpartum plays a vital role in the health of the mother and family (29, 30). Women who are better supported are less prone to health problems; thus, having a good relation within the family can contribute to the postpartum health of the mothers (15). In general, social support increases the mother's confidence and leads to a better match to the motherhood role. Results of a study displayed that social support had positive effects on self-esteem as well as the decision to participate in health-promoting practices (31). From the mothers' perspective, both spouse and family are the main sources of instrumental and emotional support (32). On the other hand, health care providers, especially nurses and midwives, can provide social support to postpartum women in the form of informational support. This revealed that, in the postpartum period, women put their own health as secondary importance. Also, the health care providers pay attention to the growth and development of a child more than the mother's mental and physical health $(17,33)$. So, our finding message for health care providers is paying attention to the role of social support and general health in health interventions. The mean of HPL in 
women in one-year postpartum was lower than that reported by Mirghafoorvand et al. (16) for Iranian women of reproductive age in 2014 and the value reported by Chen et al. (9) for postpartum Taiwanese women in 2007. Such difference in the HPL of women in the reproductive age as well as women in the first year after childbirth is not surprising. Because, many factors have a negative impact on HPL in postpartum women, such as having a responsibility for a child, body image dissatisfaction, time constraints, health problems, lack of social support, and depressive mood $(4,34)$. Health promotion is important in the postpartum period as well as during pregnancy. Unfortunately, except for family planning and breastfeeding, postpartum health promotion is less developed. Furthermore, health promotion activities started after childbirth, such as physical activity, have potential to improve women's immediate health and well-being as well as long-term benefits for reducing the risk of chronic diseases (4).

In the obtained results, the HPL dimensions with highest to lowest mean scores were: spiritual growth, interpersonal relations, health responsibility, nutrition, stress management and physical activity, which were in accordance with the findings of Gokyildiz et al. for pregnant women in Turkey (35). Participants of the present study earned the highest scores in the dimensions of spiritual growth and interpersonal relations, which were consistent with previous studies. They have suggested that when women think of pregnancy and fetal growth, their spiritual tendency increases $(36,37)$. Both pregnancy and motherhood might provide a suitable context for strengthened spirituality and encourage spiritual growth as well as a sense of closeness to God. This spirituality originates from the importance of the presence of a superior power to influence the outcome of pregnancy and delivery (38). The high scores of these women in the dimension of interpersonal relations were due to cultural backgrounds, because Iranian women who were either pregnant or in the postpartum period normally enjoyed cordial family relationships, and could count on the help of their mothers and mother in laws in supporting the care of their babies. Also, as suggested by Mirghafoorvand et al. (16), many Iranian families still live as an extended household, which ensures closer interpersonal relations. The lowest scores of participants in the present study were observed in the dimension of physical activity. It is consistent with the findings of other researchers in different target groups $(9,39)$. Low physical activity after delivery is more common. Delivery not only induces physiological changes in the body, but also the new responsibilities of the mother could contribute to limitation of physical activity (40). Considering that exercise has been reported to cause positive changes in health, low physical activity shows a need to develop a practicable exercise program for these women. Interventions should be conducted that promote HPL, particularly physical activity, among postpartum women who may have the challenge to adapt motherhood role. However, this study had some strengths and limitations. In contrast to other studies, the strength of this study was the impact assessment of general health and social support on women's HPL in late postpartum (1st year). Moreover, valid instruments were used in this study. Due to the lack of similar studies in this field, this study can be considered as a source of conductance and a basis for future studies, especially for designing the appropriate interventions for this population. This study limitation includes: First, all data are self-reported, which may have led to a misrepresentation of behaviours in findings. Second, given that general health of participants was investigated one year after delivery, potential confounding factors such as stressful events and the stress of being a parent were not incorporated into the study. Third, it should also be noted that given the cross-sectional nature of our study, the association of HPL with social support and general health cannot be interpreted as a causal relationship.

\section{Conclusions}

Delivery can affect women's health over the long term. The HPL was not at appropriate levels among women in the first year after delivery. General health had greater impact on women's health-promoting lifestyle than social support. So, these findings suggest that strengthening general health and social support would improve HPL in Iranian postpartum women. It is necessary that health care providers emphasize the importance of the family, especially their spouse and mothers as providers of social support in the postnatal period. Furthermore, the healthcare provider should learn about social support concept. Then, empower new mothers for mobilizing social support. In this study, we investigated informal social support (family, friends, and significant others). Further studies need to investigate the role of formal social support (health care professionals) and functional social support (informational, instrumental, emotional and appraisal support) in women's health promoting life style. Also, qualitative studies can provide an opportunity for health service providers to identify inhibitors and facilitators of health-promoting lifestyle in the postpartum period in accordance with women's social and cultural context.

\section{Acknowledgments:}

This report is part of a Ph.D. thesis of Tehran University of Medical Sciences. Authors of this study, greatly appreciate the Tehran University of Medical Sciences for funding this project. We would like to thank all the 
http://www.ephysician.ir

mothers and health workers at the health centers in Zanjan University of Medical Sciences, Zanjan, Iran, who made this study possible.

\section{Conflict of Interest:}

There is no conflict of interest to be declared.

\section{Authors' contributions:}

All authors contributed to this project and article equally. All authors read and approved the final manuscript.

\section{References:}

1) Matteson P. Women's health during the childbearing years: a community-based approach: Mosby; 2001.

2) Dodou HD, Rodrigues DP, Costa ACMAC, Oriá MOB, Castro RCMB, Queiroz ABA, et al. Self-care and empowerment in postpartum: social representations of puerperae. International Archives of Medicine. 2016; 9(1). doi: 10.3823/2041.

3) Mercer RT. Becoming a mother versus maternal role attainment. Journal of nursing scholarship. 2004; 36(3): 226-32. doi: 10.1111/j.1547-5069.2004.04042.x. PMID: 15495491.

4) Walker LO, Wilging S. Rediscovering the "M" in "MCH": Maternal health promotion after childbirth. J Obstet Gynecol Neonatal Nurs. 2000; 29(3): 229-36. PMID: 10839571.

5) Hammoudeh W, Mataria A, Wick L, Giacaman R. In search of health: quality of life among postpartum Palestinian women. Expert review of pharmacoeconomics \& outcomes research. 2009; 9(2): 123-32. PMID: 19402799.

6) O'Toole ML, Sawicki MA, Artal R. Structured diet and physical activity prevent postpartum weight retention. Journal of Women's Health. 2003; 12(10): 991-8. doi: 10.1089/154099903322643910. PMID: 14709187.

7) Troy NW. Is the significance of postpartum fatigue being overlooked in the lives of women? MCN Am J Matern Child Nurs. 2003; 28(4): 252-7. PMID: 12840692.

8) Barkin JL, Bloch JR, Hawkins KC, Thomas TS. Barriers to optimal social support in the postpartum period. J Obstet Gynecol Neonatal Nurs. 2014; 43(4): 445-54. PMID: 24946850.

9) Chen CM, Kuo SF, Chou YH, Chen HC. Postpartum Taiwanese women: their postpartum depression, social support and health - promoting lifestyle profiles. Journal of Clinical Nursing. 2007; 16(8): 1550-60. PMID: 17655544.

10) Gaynes BN, Gavin N, Meltzer-Brody S, Lohr KN, Swinson T, Gartlehner G, et al. Perinatal depression: Prevalence, screening accuracy, and screening outcomes. Evid Rep Technol Assess (Summ). 2005; (119): 1-8. PMID: 15760246, PMCID: PMC4780910.

11) Veisani Y, Delpisheh A, Sayehmiri K, Rezaeian S. Trends of postpartum depression in iran: a systematic review and meta-analysis. Depress Res Treat. 2013; 2013: 291029. doi: 10.1155/2013/291029. PMID: 23936640.

12) Bruwer B, Emsley R, Kidd M, Lochner C, Seedat S. Psychometric properties of the Multidimensional Scale of Perceived Social Support in youth. Comprehensive psychiatry. 2008; 49(2): 195-201. doi: 10.1016/j.comppsych.2007.09.002. PMID: 18243894.

13) Phang KN, Koh SSL, Chen Hc. Postpartum social support of women in Singapore: A pilot study. International Journal of Nursing Practice. 2015; 21(S2): 99-107. doi: 10.1111/ijn.12340. PMID: 26125577.

14) Leahy - Warren P, McCarthy G, Corcoran P. First - time mothers: social support, maternal parental self efficacy and postnatal depression. Journal of clinical nursing. 2012; $21(3$ - 4): 388-97. doi: 10.1111/j.13652702.2011.03701.x. PMID: 21435059.

15) Hung $\mathrm{CH}$, Chung $\mathrm{HH}$. The effects of postpartum stress and social support on postpartum women's health status. Journal of advanced nursing. 2001; 36(5): 676-84. doi: 10.1046/j.1365-2648.2001.02032.x. PMID: 11737500.

16) Mirghafourvand M, Baheiraei A, Nedjat S, Mohammadi E, Charandabi SM, Majdzadeh R. A populationbased study of health-promoting behaviors and their predictors in Iranian women of reproductive age. Health Promot Int. 2015; 30(3): 586-94. doi: 10.1093/heapro/dat086. PMID: 24395956.

17) Montgomery KS, Bushee TD, Phillips JD, Kirkpatrick T, Catledge C, Braveboy K, et al. Women's challenges with postpartum weight loss. Maternal and child health journal. 2011; 15(8): 1176-84. doi: 10.1007/s10995-010-0681-9. PMID: 20844941.

18) Glanz K, Rimer BK, Viswanath K. Health behavior and health education: theory, research, and practice: John Wiley \& Sons; 2008. 
19) Kline RB. Principles and Practice of Structural Equation Modeling, (Methodology In The Social Sciences). 2004.

20) Zeidi I, Hajiagha A, Zeidi B. Reliability and validity of Persian version of the health-promoting lifestyle profile. JMUMS. 2012; 22: S103.

21) Montazeri A, Harirchi AM, Shariati M, Garmaroudi G, Ebadi M, Fateh A. The 12-item General Health Questionnaire (GHQ-12): translation and validation study of the Iranian version. Health and quality of life outcomes. 2003; 1(1): 1. PMID: 14614778.

22) Bagherian-Sararoudi R, Hajian A, Ehsan HB, Sarafraz MR, Zimet GD. Psychometric properties of the Persian version of the multidimensional scale of perceived social support in Iran. Int J Prev Med. 2013; 4(11): 1277-81. PMID: 24404362, PMCID: PMC3883252.

23) Janghorbani M, Amini M, Willett WC, Gouya MM, Delavari A, Alikhani S, et al. First nationwide survey of prevalence of overweight, underweight, and abdominal obesity in Iranian adults. Obesity. 2007; 15(11): 2797-808. PMID: 18070771.

24) Cohen J. Statistical Power Analysis for the Behavioral Sciences. 2nd edn. Hillsdale: Earlbaum; 1988.

25) Cheng CY, Pickler RH. Effects of stress and social support on postpartum health of Chinese mothers in the United States. Research in nursing \& health. 2009; 32(6): 582-91. PMID: 19877163.

26) Panzarine S, Slater E, Sharps P. Coping, social support, and depressive symptoms in adolescent mothers. Journal of Adolescent Health. 1995; 17(2): 113-9. PMID: 7495822.

27) Chenary R, Noroozi A, Tavafian SS, Firoozabadi MS. Effective Factors on Health-Promoting Lifestyle Among Iranian Chemical Veterans in 2014 Based on Health Promotion Model: A Path Analysis. Iran Red Crescent Med J. 2016; 18(8): e33467. doi: 10.5812/ircmj.33467. PMID: 27781120, PMCID: PMC5065710.

28) Cotter KA. No Strain, No Gain: An Application of Social Cognitive Theory to Physical Activity Across the Lifespan: ProQuest; 2008.

29) Emmanuel E, St John W, Sun J. Relationship between social support and quality of life in childbearing women during the perinatal period. Journal of Obstetric, Gynecologic, \& Neonatal Nursing. 2012; 41(6): E62-70. PMID: 22861382.

30) Ohashi Y, Asano M. Transition to early parenthood, and family functioning relationships in Japan: a longitudinal study. Nursing \& health sciences. 2012; 14(2): 140-7. doi: 10.1111/j.1442-2018.2011.00669.x. PMID: 22316497.

31) Muhlenkamp AF, Sayles JA. Self-esteem, social support, and positive health practices. Nursing Research. 1986; 35(6): 334-8. doi: 10.1097/00006199-198611000-00007. PMID: 3640349.

32) Negron R, Martin A, Almog M, Balbierz A, Howell EA. Social support during the postpartum period: mothers' views on needs, expectations, and mobilization of support. Maternal and child health journal. 2013; 17(4): 616-23. doi: 10.1007/s10995-012-1037-4. PMID: 22581378, PMCID: PMC3518627.

33) Fowles ER, Cheng HR, Mills S. Postpartum health promotion interventions: A systematic review. Nursing research. 2012; 61(4): 269-82. doi: 10.1097/NNR.0b013e3182556d29. PMID: 22592390.

34) Groth SW, David T. New mothers' views of weight and exercise. MCN The American journal of maternal child nursing. 2008; 33(6): 364. doi: 10.1097/01.NMC.0000341257.26169.30. PMID: 18997572, PMCID: PMC2712877.

35) Gokyildiz S, Alan S, Elmas E, Bostanci A, Kucuk E. Health - promoting lifestyle behaviours in pregnant women in Turkey. International journal of nursing practice. 2014; 20(4): 390-7. doi: 10.1111/ijn.12187. PMID: 24118372.

36) Jesse DE, Reed PG. Effects of spirituality and psychosocial well - being on health risk behaviors in Appalachian pregnant women. Journal of Obstetric, Gynecologic, \& Neonatal Nursing. 2004; 33(6): 73947. doi: $10.1177 / 0884217504270669$. PMID: 15561662.

37) Grace SL, Williams A, Stewart DE, Franche RL. Health-promoting behaviors through pregnancy, maternity leave, and return to work: effects of role spillover and other correlates. Women \& Health. 2006; 43(2): 51-72. doi: 10.1300/J013v43n02_04. PMID: 17000611.

38) Callister LC, Khalaf I. Spirituality in childbearing women. The Journal of perinatal education. 2010; 19(2): 16-24. PMID: 20498751.

39) Baheiraei A, Mirghafourvand M, Charandabi SM, Mohammadi E, Nedjat S. Health-promoting behaviors and social support in Iranian women of reproductive age: a sequential explanatory mixed methods study. International journal of public health. 2014; 59(3): 465-73. PMID: 24042269.

40) Bahadoran P, Tirkesh F, Oreizi HR. Association between physical activity 3-12 months after delivery and postpartum well-being. Iran J Nurs Midwifery Res. 2014; 19(1): 82. PMID: 24554965. 